\title{
On Axiom Systems of Słupecki for the Functionally Complete Three-Valued Logic
}

\author{
Mateusz M. Radzki ${ }^{1}$
}

Received: 17 July 2016/Accepted: 17 October 2016/Published online: 7 November 2016

(C) The Author(s) 2016. This article is published with open access at Springerlink.com

\begin{abstract}
The article concerns two axiom systems of Słupecki for the functionally complete three-valued propositional logic: W1-W6 (from 1936) and A1-A9 (from 1946). The article proves that both of them are inadequate-W1-W6 is semantically incomplete, on the other hand, A1-A9 governs a functionally incomplete calculus, and thus, it cannot be a semantically complete axiom system for the functionally complete three-valued logic.
\end{abstract}

Keywords Functional incompleteness - Semantic incompleteness - Słupecki's axiom systems - Three-valued logic

\section{Introduction}

In the article, we concern two axiom systems of Jerzy Słupecki for the functionally complete three-valued propositional logic. We prove that both of them are inadequate - the first one is semantically incomplete, on the other hand, the second one governs a functionally incomplete calculus, and thus, it cannot be a semantically complete axiom system for the functionally complete three-valued logic.

Jan Łukasiewicz in his works published in the early 1920s, introduced the third, intermediate truth-value $1 / 2$. The remaining two, i.e., 1 (interpreted as the true) and 0 (interpreted as the false), were well-known from the classical logic. Adding another truth-value different from the classical ones was the first step in constructing various systems of many-valued logic (Avron 1991, p. 277; Epstein 1993, p. 8; Fullér 2000,

Mateusz M. Radzki

matradzki@wp.pl

1 Institute of Philosophy and Sociology, The Maria Grzegorzewska University, ul. Szczęśliwicka 40, 02-353 Warsaw, Poland 
p. 1; He et al. 2007, p. 86; Schumann and Smarandache 2007, p. 27; Zhang et al. 2005, pp. 9-10).

Łukasiewicz's discovery was the result of many philosophical debates within the Polish Lvov-Warsaw School. Grzegorz Malinowski writes:

[...] among the factors which prompted Łukasiewicz's views on logics and which persuaded him to abandon the classical perspective, one may mention the following three: 1. The discussion, within the Lvov-Warsaw School, of the general theory of objects that had been proposed by Brentano, Twardowski and Meinong; 2. Łukasiewicz's investigation into the problems of induction and the theory of probability; 3. his examination of the question of determinism, indeterminism and related problems concerning causality and modality (Malinowski 2009, pp. 81-82).

It should be noted that in the field of metaphysical investigations into the nature of objects, Łukasiewicz accepted the idea of contradictory objects, i.e., objects that have contradictory properties; in the theory of induction and probability, Łukasiewicz developed the idea of fractional "logical values" which are relative, and finally, in the theory of indeterminism and causality, Łukasiewicz established a third "logical value" that is attributed to propositions describing future events (Malinowski 2009, p. 83). Therefore, the scope of philosophical investigations that are ranged by Łukasiewicz's reasoning is quite wide. It includes both metaphysical, modal and even ethical concepts. Jan Woleński points out that

[...] the philosophical context of the construction of many-valued logics in Poland was linked to discussions on determinism, indeterminism, possibility, necessity, and freedom. [...] Eukasiewicz paid attention to the intuitive interpretation of many-valued logics, but with the lapse of time those logics started to live a life of their own as formal constructions (Woleński 1989, p. 124; compare with Murawski 2009, pp. 122-123).

Moreover, we can indicate a more general claim behind certain metaphysical and modal ideas of Łukasiewicz's philosophy. In the paper that appeared originally in 1930, Łukasiewicz emphasizes:

I would perhaps not be right to call the many-valued systems of propositional logic established be me 'non-Aristotelian' logic, as Aristotle himself was the first to have thought that the law of bivalence could not be true for certain propositions. [...] However, it seems to me that the philosophical significance of the systems of logic treated here might be at least as great as the significance of non-Euclidean geometry (Łukasiewicz 1967, p. 63).

Alasdair Urquhart explains Łukasiewicz's motivation:

[...] many-valued logic was not just a mathematical toy for Łukasiewicz, but rather a weapon of most fundamental importance in his fight against the mental strait-jacket of Aristotelian logic, a weapon that he classed with nonEuclidean geometry as a tool which released the human mind from the tyranny 
of rigid intellectual systems (Urquhart 2001, p. 249; compare with Priest 2003, pp. 442-443; Simons 1989, p. 251).

This standpoint was determined by philosophical debates within the LvovWarsaw School. As the result of them, Łukasiewicz was persuaded to reject the classical "law of contradiction" which in the classical propositional logic is expressed by the tautology $\sim(p \wedge \sim p)$ (see, Wan and Chen 2014, p. 196). It was the first philosophical step towards introducing a many-valued logic. Nicholas Rescher writes: "The motivation afforded by the idea of overcoming the classical 'Law of Contradiction' was a major impetus in the development of many-valued logics" (Rescher 1968, p. 107).

Then, the rejection of $\sim(p \wedge \sim p)$ led Łukasiewicz to abandon the classical twovalued logic, and to introduce the third truth-value $1 / 2$. In other words, the rejection of $\sim(p \wedge \sim p)$ persuaded Łukasiewicz to violate the principle of bivalence, according to which every proposition is either true or false. John B. Rosser and Atwell R. Turquette write:

Ever since there was first a clear enunciation of the principle "Every proposition is either true or false", there have been those who questioned it. With the development of an axiomatic treatment of logic, it has become possible to construct systems of logic in which this principle is not valid. One way to obtain a usable set of axioms for such a purpose is to replace this principle by an alternative one such as "Every statement is true or false or tertium". One's first reaction to this might be that henceforth we no longer have the principle of reductio ad absurdum. Certainly, we no longer have it in the familiar form of a "tertium non datur". Instead, we have a generalized form which may be called a "quartum non datur" (Rosser and Turquette 1952, p. 10).

For Łukasiewicz, another philosophical motivation for constructing three-valued calculus was an intention to describe by means of logic the contingent nature of the future states of affairs (see, for example, Gottwald 1999, p. 12; Grandy 2006, p. 532; Haack 1996, pp. 73-74; Humberstone 2011, p. 196; Malinowski 2009, pp. 82-83; Mattila 2009, p. 272; Prior 1953, p. 323; Sudbery 2016, pp. 7-8; Tomberlin 1971, p. 353; Tooley 1997, p. 133; Wan and Chen 2014, p. 196). Susan Haack emphasizes that "The 'problem of future contingents' provided the motivation for one of the pioneer investigations of many-valued logics" (Haack 1996, p. 73).

According to Łukasiewicz, the truth-value $1 / 2$ has a philosophical meaning referring to the possible, or rather contingent, nature of the future states of affairs. Thus, $1 / 2$ is assigned to propositions on the future states of affairs that are neither true nor false, but which are only possibly true and possibly false (contingently true). Łukasiewicz explains:

I can assume without contradiction that my presence in Warsaw at a certain moment of the next year, e.g., at noon on 21 December, is at the present time determined neither positively nor negatively. Hence it is possible, but not necessary, that I shall be present in Warsaw at the given time. On this assumption the proposition 'I shall be in Warsaw at noon on 21 December of 
next year', can at the present time be neither true nor false. [...] Therefore the proposition considered is at the moment neither true nor false and must possess a third value, different from ' 0 ' or falsity and from ' 1 ' or truth. This value we can designate by ' $1 / 2$ '. It represents 'the possible', and joins 'the true' and 'the false' as a third value (Łukasiewicz 1967, p. 53).

Although Łukasiewicz criticized the classical logic of Aristotle, he accepted two fundamental principles which govern almost all logical systems-from the classical logic to various non-classical logics (Urquhart 2001, p. 251). The first principle refers to the syntactic side of logic. It asserts that logic should be formulated using axioms, the rule of detachment (hereinafter MP), and the rule of substitution (hereinafter SUB). According to the second principle (the socalled "principle of compositionality" or "truth-functionality") which refers to the semantic side of logic, the values of complex propositions should be a function of the respective values of their components (see, for example, Gottwald 2001, p. 4).

Łukasiewicz constructed the truth-tables for the familiar propositional connectives, i.e., $\sim, \rightarrow, \vee, \wedge, \leftrightarrow$. According to Rescher, we can identify five general principles which govern the semantic side of Łukasiewicz's three-valued logic (hereinafter $\mathrm{L}_{3}$ ):

(1) There are three truth-values, 1, 1/2, 0 (in the decreasing order of 'truthfulness'); (2) The negation of a statement of given truth-values is its 'opposite' in truthfulness; (3) The truth-value of a conjunction is the falsest (and of a disjunction the truest) of the truth-values of its components; (4) The truth-value of ' $p \rightarrow q$ ' is the same as that of ' $\sim p \vee q$ ' except that the truthvalue corresponding to $1 / 2 \rightarrow 1 / 2$ is a set at 1 (to assure that ' $p \rightarrow p$ ' will invariably assume the truth-value 1); (5) The truth-value of ' $p \leftrightarrow q$ ' is the same as that of ' $(p \rightarrow q) \wedge(q \rightarrow p)$ ' (Rescher 1968, p. 65).

Therefore, let $\mathrm{L}_{\mathrm{L}_{3}}$ be a propositional language of $\mathrm{L}_{3}$ defined as the following algebra (see, for example, Wójcicki 1973, pp. 12-13):

$$
\mathrm{L}_{\mathrm{L}_{3}}=\left(\mathrm{FOR}_{\mathrm{L}_{3}}, \sim, \rightarrow, \vee, \wedge, \leftrightarrow\right),
$$

where $\mathrm{FOR}_{\mathrm{L}_{3}}$ is a set of wffs of $\mathrm{L}_{3}$.

Then let $\mathfrak{M}_{\mathrm{L}_{3}}$ be a logical matrix for $\mathrm{L}_{3}$, i.e.,

$$
\mathfrak{M}_{\mathrm{L}_{3}}=\left(\mathrm{A}_{\mathrm{L}_{3}},\{1\}\right) \text {, }
$$

where $\mathrm{A}_{\mathrm{L}_{3}}=(\{1,1 / 2,0\}, \sim, \rightarrow, \vee, \wedge, \leftrightarrow)$.

In $\mathrm{L}_{3}$, the connectives $\sim, \rightarrow, \vee, \wedge, \leftrightarrow$ are defined by the following truthtables (in the truth-tables for $\rightarrow, \vee, \wedge, \leftrightarrow$, the truth-value of $p$ is given in the vertical line, the truth-value of $q$ is given in the horizontal line, and the truth-value of $p \circ q$ ( $\circ=\rightarrow, \vee, \wedge, \leftrightarrow$ ) is given in the intersection of these lines) (see, for example, Chen and Pham 2001, p. 65; Łukasiewicz 1967, p. 54; Malinowski 2006, p. 546; Nguyen and Walker 2000, p. 66; Tooley 1997, p. 134; Wan and Chen 2014, p. 196): 


\begin{tabular}{|c|c|c|c|c|c|c|c|c|c|}
\hline$p$ & $\sim p$ & $\rightarrow$ & 0 & $1 / 2$ & 1 & V & 0 & $1 / 2$ & 1 \\
\hline 0 & 1 & 0 & 1 & 1 & 1 & 0 & 0 & $1 / 2$ & 1 \\
\hline $1 / 2$ & $1 / 2$ & $1 / 2$ & $1 / 2$ & 1 & 1 & $1 / 2$ & $1 / 2$ & $1 / 2$ & 1 \\
\hline 1 & 0 & 1 & 0 & $1 / 2$ & 1 & 1 & 1 & 1 & 1 \\
\hline
\end{tabular}

\begin{tabular}{|c|c|c|c|c|c|c|c|}
\hline$\wedge$ & 0 & $1 / 2$ & 1 & $\leftrightarrow$ & 0 & $1 / 2$ & 1 \\
\hline 0 & 0 & 0 & 0 & 0 & 1 & $1 / 2$ & 0 \\
\hline $1 / 2$ & 0 & $1 / 2$ & $1 / 2$ & $1 / 2$ & $1 / 2$ & 1 & $1 / 2$ \\
\hline 1 & 0 & $1 / 2$ & 1 & 1 & 0 & $1 / 2$ & 1 \\
\hline
\end{tabular}

It is well-known that according to Mordchaj Wajsberg (Wajsberg 1967; compare, for example, with Bergmann 2008, p. 100; Cignoli et al. 2000, pp. 87-88; Ciucci and Dubois 2012, p. 155; Goldberg and Weaver 1982, p. 240; Gottwald 2001, p. 195; Kabziński 1981, p. 206; Słupecki et al. 1967, p. 52), taking MP and SUB, L ${ }_{3}$ is axiomatized by the four axioms:

$$
\mathrm{W} 1 . p \rightarrow(q \rightarrow p)
$$

$$
\begin{gathered}
\text { W2. }(p \rightarrow q) \rightarrow((q \rightarrow r) \rightarrow(p \rightarrow r)), \\
\text { W3. }(\sim p \rightarrow \sim q) \rightarrow(q \rightarrow p), \\
\text { W4. }((p \rightarrow \sim p) \rightarrow p) \rightarrow p .
\end{gathered}
$$

The remaining propositional connectives are defined as follows:

$$
\begin{gathered}
(p \vee q) \stackrel{\mathrm{DEF}}{\leftrightarrow}((p \rightarrow q) \rightarrow q), \\
(p \wedge q) \stackrel{\mathrm{DEF}}{\leftrightarrow} \sim(\sim p \vee \sim q), \\
(p \leftrightarrow q) \stackrel{\mathrm{DEF}}{\leftrightarrow}((p \rightarrow q) \wedge(q \rightarrow p)) .
\end{gathered}
$$

It should be noted that every propositional connective of $\mathrm{L}_{3}$ possesses a special property-every one of them is a "normal" connective (Rescher 1968, p. 79; Rescher 1969, pp. 55-56). This means that if each argument of a truth-function corresponding to any connective of $\mathrm{L}_{3}$ is either 1 or 0 , then this truth-function assumes either 1 or 0 (Rescher 1968, pp. 78-79). As Rescher explains:

The truth-table for a propositional connective that is the many-valued analogue of one of the two-valued connectives will be said to be normal, if it includes at least one trueanalogous truth-value $\mathrm{T}$ (which, however, may be 
designated by 0 or 1 or $n$ or in some other way) and at least one falseanalogous truth-value F (also perhaps differently designated), and this many-valued table agrees entirely with the standard two-valued one for the connective in $C$ [i.e., in the classical logic] when only the two truth-values $\mathrm{T}$ and $\mathrm{F}$ are involved. A many-valued logic may be said to be normal (as a whole), if the truth-tables for all of its basic connectives are normal (with respect to one and the same pair of truth-valued T, F) (Rescher 1968, pp. 78-79).

In other words, every truth-table for a propositional connective in a normal many-valued propositional logic is an extension of the truth-table for the analogous connective in the classical logic.

It is easy to recognize that $\mathrm{L}_{3}$ is a normal logic. For example, let us consider the truth table for $\rightarrow$ in $\mathrm{L}_{3}$ :

\begin{tabular}{|c|c|c|c|}
\hline$\rightarrow$ & $\mathbf{0}$ & $1 / 2$ & $\mathbf{1}$ \\
\hline $\mathbf{0}$ & $\mathbf{1}$ & 1 & $\mathbf{1}$ \\
\hline $1 / 2$ & $1 / 2$ & 1 & 1 \\
\hline $\mathbf{1}$ & $\mathbf{0}$ & $1 / 2$ & $\mathbf{1}$ \\
\hline
\end{tabular}

The part of this truth-table that is marked with bold 1 and 0 agrees entirely with the truth-table for $\rightarrow$ in the classical logic. The other part concerns only cases in which $1 / 2$ is involved as an argument. If we considered the remaining connectives in $\mathrm{L}_{3}$, we would obtain the same result-every truth-table for each connective in $\mathrm{L}_{3}$ is an extension of the truth-table for the analogous connective in the classical logic.

A moment of reflection shows that every propositional connective that lacks of the property of being a normal one, cannot be defined just in terms of some normal connectives. In other words, if a truth-function assumes $1 / 2$ for the arguments 1 or 0 , it cannot be defined just by means of the truth-functions that do not assume $1 / 2$ for the arguments 1 or 0 .

However, it is easy to define a truth-function that corresponds to a certain connective, and assumes, for example, $1 / 2$ for the argument 1 . Then, this connective is not a normal one, and it cannot be defined in terms of the familiar $\sim, \rightarrow, \vee, \wedge, \leftrightarrow$ of $\mathrm{L}_{3}$. Therefore, $\mathrm{L}_{3}$ is not a functionally complete logic (Malinowski 2007, p. 37).

In his article from 1936 (Słupecki 1967; see also Bolc and Borowik 1992, p. 64; Rosser and Turquette 1952, pp. 23-25), Słupecki, to have the functionally complete $\mathrm{L}_{3}$, extended the axiom system $\mathrm{W} 1-\mathrm{W} 4$ adding further two axioms:

$$
\begin{aligned}
& \text { W5. } T p \rightarrow \sim T p, \\
& \text { W6. } \sim T p \rightarrow T p .
\end{aligned}
$$


The Słupecki's T-function (Date 2007, p. 138; Epstein 1995, p. 323) is defined by the following truth-table:

\begin{tabular}{|c|c|}
\hline$p$ & $T p$ \\
\hline 0 & $1 / 2$ \\
\hline $1 / 2$ & $1 / 2$ \\
\hline 1 & $1 / 2$ \\
\hline
\end{tabular}

Although Słupecki postulated the semantic completeness of the axiom system W1-W6 (Słupecki 1967, p. 336), in Sect. 2, we shall demonstrate that not all tautologies of the functionally complete $\mathrm{L}_{3}$ that are constructed out of $\sim, \rightarrow$ and $T$ are provable in W1-W6. Hence, W1-W6 is not a semantically complete axiom system.

In his paper from 1946 (Słupecki 1946; see also Bolc and Borowik 1992, p. 76), Słupecki introduced, as he claimed, another functionally complete three-valued propositional logic (hereinafter $\mathrm{S}_{3}$ ).

Since both $\mathrm{S}_{3}$ and $\mathrm{L}_{3}$ are three-valued logics, and in both of them, a single truthvalue is distinguished, if $\mathrm{S}_{3}$ were a functionally complete logic, then, provided that we unify the manner of defining the truth-values, and establish the true as a distinguished one, we could consider $S_{3}$ to be equal to the functionally complete $\mathrm{L}_{3}$ - under such conditions, every propositional connective of $\mathrm{S}_{3}$ would be defined by means of connectives of the functionally complete $\mathrm{L}_{3}$, and, on the other hand, every propositional connective of the functionally complete $\mathrm{L}_{3}$, including $T$, would be defined by means of connectives of $S_{3}$. Hence, every tautology of $S_{3}$ would be a tautology of the functionally complete $\mathrm{L}_{3}$, and vice versa, every tautology of the functionally complete $\mathrm{L}_{3}$ would be a tautology of $\mathrm{S}_{3}$.

That is why in the presented exposition, we use consistently Łukasiewicz's manner of defining the truth-values, and hence, 1 stands for the true, 0 stands for the false, and $1 / 2$ stands for the intermediate truth-value. Similarly as in $\mathrm{L}_{3}, 1$ is a distinguished truthvalue in $S_{3}$. Although the manner of defining the truth-values has no impact to the line of our reasoning, it makes the comparison of $\mathrm{S}_{3}$ with $\mathrm{L}_{3}$ more readable.

Hence, let $S_{3}$ be given by the matrix:

$$
\mathfrak{M}_{\mathrm{S}_{3}}=(\{1,1 / 2,0\},-, \neg, \Rightarrow,\{1\}) .
$$

Then, we can characterize the propositional connectives of $S_{3}$ as follows:

\begin{tabular}{|c|c|c|c|c|c|c|c|}
\hline$p$ & $-p$ & $\neg p$ & $\Rightarrow$ & 0 & $1 / 2$ & 1 \\
\hline 0 & 1 & 1 & 0 & 1 & 1 & 1 \\
\cline { 1 - 2 } & 1 & 1 & $1 / 2$ & 1 & 1 & 1 \\
\hline 1 & 0 & $1 / 2$ & 1 & 0 & $1 / 2$ & 1 \\
\hline
\end{tabular}


Taking MP and SUB, Słupecki introduced the following axioms for $\mathrm{S}_{3}$ :

$$
\begin{gathered}
\text { A1. }(p \Rightarrow q) \Rightarrow((q \Rightarrow r) \Rightarrow(p \Rightarrow r)), \\
\text { A2. }(\neg p \Rightarrow p) \Rightarrow p, \\
\text { A3. } p \Rightarrow(\neg p \Rightarrow q), \\
\text { A4. }-p \Rightarrow \neg p, \\
\text { A5. }-(p \Rightarrow q) \Rightarrow-q, \\
\text { A6. } p \Rightarrow(-q \Rightarrow-(p \Rightarrow q)), \\
\text { A7. }--p \Rightarrow p, \\
\text { A8. } p \Rightarrow--p, \\
\text { A9. } \neg-\neg p \Rightarrow-p .
\end{gathered}
$$

Although A1-A9 was formulated as another variant of an axiom system for the functionally complete three-valued calculus, in Sect. 3, we shall show that not every truth-function can be defined in terms of $\{-, \neg, \Rightarrow\}$, and thus, A1-A9 cannot be a semantically complete axiom system for the functionally complete three-valued logic.

\section{Semantic Incompleteness of W1-W6}

It is not difficult to verify that the following formulae

$$
\begin{gathered}
T p \rightarrow \sim T q, \\
\sim T q \rightarrow T p
\end{gathered}
$$

are tautologies of the functionally complete $\mathrm{L}_{3}$. Thus, if Słupecki's axiom system is semantically complete, they are provable in W1-W6.

However, the contrary result can be obtained. The proof follows the prooftheoretic method of proving in any formal system that an arbitrary axiom is independent of the set of the other axioms. As Geoffrey Hunter explains:

[...] let $\mathrm{A}$ be the axiom we are interested in. If we can show that all the other axioms have a certain syntactic property, that this property is transmitted by the rule(s) of inference, and that A does not have that property, then $\mathrm{A}$ is independent of the other axioms (Hunter 1971, p. 122; compare also with Negri and von Plato 2001, p. 139).

Then, we can use this method to prove that a certain formula of the functionally complete $\mathrm{L}_{3}$ is not provable in the axiom system W1-W6. 
Proof Let L' be a formula that results from a formula of the functionally complete $\mathrm{L}_{3}$, i.e., $\mathrm{L}$, by deleting the following sequences of signs: $T$ and $\sim T$. Call $\mathrm{L}^{\prime}$ the 'formula associated' with $\mathrm{L}$. Then, the formulae associated with $\mathrm{W} 1, \mathrm{~W} 2, \mathrm{~W} 3$ and $\mathrm{W} 4$ are tautologies of the functionally complete $\mathrm{L}_{3}$ (in these cases, $\mathrm{L}^{\prime}=\mathrm{L}$ ). Also the formulae associated with W5 and W6 are tautologies of the functionally complete $\mathrm{L}_{3}$ (in these cases, $\mathrm{L}^{\prime}=p \rightarrow p$ ). MP preserves the tautologyhood of the associated formulae (if $A$ and $B$ are arbitrary formulae of the functionally complete $\mathrm{L}_{3}$, then $\left.(A \rightarrow B)^{\prime}=\left(A^{\prime} \rightarrow B^{\prime}\right)\right)$. However, the formulae associated with $T p \rightarrow \sim T q$ and $\sim T q \rightarrow T p$, i.e., $p \rightarrow q$ and $q \rightarrow p$, respectively, are not tautologies of the functionally complete $\mathrm{L}_{3}$. Therefore, $T p \rightarrow \sim T q$ and $\sim T q \rightarrow T p$ are not provable in W1-W6.

Nevertheless, it might arise a question: if W5 and W6 were replaced, for example, with

$$
\begin{aligned}
& \mathrm{W}^{\prime} . T p \rightarrow \sim T q \\
& \mathrm{~W}^{\prime} . T p \rightarrow \sim T q
\end{aligned}
$$

respectively, would such modified axiom system be semantically complete?

Hence, let us consider the following formula

$$
((T p \rightarrow T q) \rightarrow T q) \rightarrow T r
$$

which is a tautology of the functionally complete $\mathrm{L}_{3}$. Thus, if such modified axiom system of Słupecki, call it $\mathrm{W} 1-\mathrm{W} 5^{\prime}-\mathrm{W} 6^{\prime}$, were semantically complete, $((T p \rightarrow T q) \rightarrow T q) \rightarrow T r$ would be provable in $\mathrm{W} 1-\mathrm{W} 5^{\prime}-\mathrm{W} 6^{\prime}$.

However, it can be demonstrated that the formula $((T p \rightarrow T q) \rightarrow T q) \rightarrow T r$ is not provable in $\mathrm{W} 1-\mathrm{W}^{\prime}-\mathrm{W}^{\prime}$. The proof is similar to the previous one.

Proof Let $\mathrm{L}^{\prime}$ be a formula that results from a formula of the functionally complete $\mathrm{L}_{3}$, i.e., L, by substituting $q$ with $p$, and by deleting the following sequences of signs: $T$ and $\sim T$. $\mathrm{L}^{\prime}$ is the 'formula associated' with $\mathrm{L}$. Thus, the formulae associated with $\mathrm{W} 1, \mathrm{~W} 2, \mathrm{~W} 3$ and $\mathrm{W} 4$ are tautologies of the functionally complete $\mathrm{L}_{3}$ (in these cases, $\mathrm{L}^{\prime}$ are substitutions instances of $\mathrm{L}$ ). Also the formulae associated with $\mathrm{W}^{\prime}$ and $\mathrm{W}^{\prime}$ are tautologies of the functionally complete $\mathrm{L}_{3}$ (in these cases, $\mathrm{L}^{\prime}=p \rightarrow p$ ). MP preserves the tautologyhood of the associated formulae (if $A$ and $B$ are arbitrary formulae of functionally complete $\mathrm{L}_{3}$, then $\left.(A \rightarrow B)^{\prime}=\left(A^{\prime} \rightarrow B^{\prime}\right)\right)$. However, the formulae associated with $\quad((T p \rightarrow T q) \rightarrow T q) \rightarrow T r$, i.e., $((p \rightarrow p) \rightarrow p) \rightarrow r$, is not a tautology of the functionally complete $\mathrm{L}_{3}$. Consequently, $((T p \rightarrow T q) \rightarrow T q) \rightarrow T r$ is not provable in $\mathrm{W} 1-\mathrm{W}^{\prime}-\mathrm{W} 6^{\prime}$.

\section{Functional Incompleteness of A1-A9}

Now, let us consider $\mathrm{A} 1-\mathrm{A} 9$ for $\mathrm{S}_{3}$. If $\mathrm{S}_{3}$ is a functionally complete three-valued calculus, then every truth-function of a three-valued logic is definable in terms of $\{-, \neg, \Rightarrow\}$.

Then, consider the truth-function characterized by the following truth-table: 


\begin{tabular}{|c|c|}
\hline$p$ & $\circ p$ \\
\hline 0 & 0 \\
\hline $1 / 2$ & $1 / 2$ \\
\hline 1 & 0 \\
\hline
\end{tabular}

Let us examine the definability of op in terms of $\{-, \neg, \Rightarrow\}$. Let $A$ and $B$ be arbitrary formulae of $S_{3}$. Since $-A$ never takes on the truth-value $1 / 2$, and $\neg A$ never takes on the truth-value 0 , op is definable neither by $-A$ nor by $\neg A$. Then, if $\mathrm{S}_{3}$ is a functionally complete logic, op is definable by $A \Rightarrow B$. However, the contrary result can be obtained.

Proof Assume op is definable by $A \Rightarrow B$. Thus, if $p$ takes on the truth-value 0 , then $A \Rightarrow B$ takes on the truth-value 0 which means that $A$ takes on the truth-value 1 , and $B$ takes on the truth-value 0 . If $p$ takes on the truth-value $1 / 2$, then $A \Rightarrow B$ takes on the truth-value $1 / 2$ which means that $A$ takes on the truth-value 1 , and $B$ takes on the truth-value $1 / 2$. If $p$ takes on the truth-value 1 , then $A \Rightarrow B$ takes on the truthvalue 0 which means that $A$ takes on the truth-value 1 , and $B$ takes on the truth-value 0 . Hence, if $p$ takes on the truth-value 0 , then $B$ takes on the truth-value 0 . If $p$ takes on the truth-value $1 / 2$, then $B$ takes on the truth-value $1 / 2$. If $p$ takes on the truth-value 1 , then $B$ takes on the truth-value 0 . Notice that the only one propositional variable that occurs in $A \Rightarrow B$ is $p$. Therefore, if op is definable by $A \Rightarrow B$, then $B$ is a definition of $o p$. This means that if we want to define $o p$, op needs to be already defined. Consequently, op is indefinable by $A \Rightarrow B$.

Hence, $\circ p$ is definable neither by $-A$ nor by $\neg A$, nor by $A \Rightarrow B$. This means that $\mathrm{S}_{3}$ is not a functionally complete calculus. Since just $-\neg$, and $A \Rightarrow B$ are the primitive connectives of A1-A9, A1-A9 governs a functionally incomplete logic. Therefore, A1-A9 cannot be a semantically complete axiom system for the functionally complete three-valued logic.

\section{Conclusions}

We have proved that although, as Słupecki demonstrated in his article (Słupecki 1967; see also Evans and Schwartz 1958, p. 267; Karpenko 1989, p. 467; Rose 1981, p. 124; Skala 1988, p. 3; Woleński and Zygmunt 1989, p. 405), every propositional connective of the functionally complete $\mathrm{L}_{3}$ is definable in terms of $\{\sim, \rightarrow, T\}$, Słupecki's axiom system W1-W6 is semantically incomplete. In other words, Słupecki's two axioms added to Wajsberg's axiom system are not sufficient to obtain all tautologies of the functionally complete $\mathrm{L}_{3}$ which are constructed out of $\sim, \rightarrow$ and $T$. This conclusion is contrary to the common point of view that by $\mathrm{W} 1-$ W6, the functionally complete $\mathrm{L}_{3}$ is axiomatized (see, for example, Bergmann 2008, p. 94; Bolc and Borowik 1992, p. 64; Mancosu et al. 2009, p. 418; Mancosu 2010, p. 97 ; Urquhart 2001, p. 266). 
Moreover, in the article, we have considered another variant of Słupecki's functionally complete three-valued logic, i.e., $S_{3}$ with three connectives,$- \neg$, and $\rightarrow$. Since both $L_{3}$ and $S_{3}$ are three-valued, and in both of them a single truth-value is distinguished, if $S_{3}$ were functionally complete, then, under certain conditions, we could consider $S_{3}$ to be equal to the functionally complete $L_{3}$, i.e., the set of tautologies of $\mathrm{S}_{3}$ would be equal to the set of tautologies of $\mathrm{L}_{3}$. However, we have demonstrated that not every truth-function is defined in terms of $\{-, \neg, \Rightarrow\}$, and thus, $\mathrm{S}_{3}$ is functionally incomplete. Therefore, Słupecki's axiom system A1-A9 with the primitive connectives,$- \neg$, and $\rightarrow$ cannot be a semantically complete axiom system for the functionally complete three-valued logic.

Nevertheless, it might arise a question what is the importance of our result other then critical examination and refutation of Słupecki's axiom systems? We can answer that by overthrowing false theories we are closer to the truth. It should be noted that not only in the empirical sciences, but also in logic, mathematics and philosophy, one can choose two ways for reaching the truth: by constructing correct theories or by rejecting incorrect ones. In the present article, we have chosen the second way. But this way is not less important in science then the first one, especially for logicians who strive for eliminating false theories in the scientific reasoning.

However, it might be argued that these two ways are inevitably interlaced. Usually, to introduce a new theory, we need to refute an old one. On the other hand, an overthrown old theory needs to be replaced by a new one. Although in the literature, we can find a couple of general methods of constructing axiom systems for the manyvalued logics, for example the method of Rosser and Turquette for both the finitevalued logics of Łukasiewicz and the logics of Emil Post (Gottwald 2001, pp. 107-110; Malinowski 2006, p. 552; Malinowski 2007, pp. 37-38), the method of Revaz Grigolia for $n$-valued $(n>3)$ logics of Łukasiewicz (Grigolia 1997, pp. 81-92), the systems of Marek Tokarz (Tokarz 1974, pp. 21-24) and Roman Tuziak (Tuziak 1988, p. 50) for the $n$-valued ( $n \geq 2$ ) logics of Łukasiewicz, and the method of Słupecki for the functionally complete $n$-valued $(n>3) \operatorname{logics}$ (Słupecki 1939, pp. 110-128; compare also with Bolc and Borowik 1992, pp. 79-82), the known axiom systems for the commonly investigated functionally complete three-valued calculus with a single designated truth-value are only those constructed by Słupecki. Therefore, our final result is to reveal the need for constructing new axiom system for the functionally complete three-valued propositional logic.

Open Access This article is distributed under the terms of the Creative Commons Attribution 4.0 International License (http://creativecommons.org/licenses/by/4.0/), which permits unrestricted use, distribution, and reproduction in any medium, provided you give appropriate credit to the original author(s) and the source, provide a link to the Creative Commons license, and indicate if changes were made.

\section{References}

Avron A (1991) Natural 3-valued logics - characterization and proof theory. J Symb Log 56:276-294 Bergmann M (2008) An introduction to many-valued and fuzzy logic. Cambridge University Press, Cambridge 
Bolc L, Borowik P (1992) Many-valued logics 1: theoretical foundations. Springer, Berlin

Chen G, Pham TT (2001) Introduction to fuzzy sets, fuzzy logic, and fuzzy control systems. CRC Press, London

Cignoli RLO, D’Ottaviano IML, Mundici D (2000) Algebraic foundations of many-valued reasoning. Springer Science + Business Media, Dordrecht

Ciucci D, Dubois D (2012) Three-valued logics for incomplete information and epistemic logic. In: Goebel R et al (eds) Lectures notes in artificial intelligence. Springer, Berlin, pp 147-159

Date CJ (2007) Logic and databases: the roots of relational theory. Trafford Publishing, Bloomington

Epstein RL (1993) Multiple-valued logic design: an introduction. Institute of Physics Publishing, Bristol Epstein RL (1995) Propositional logics. Oxford University Press, Oxford

Evans T, Schwartz PB (1958) On Słupecki’s T-functions. J Symb Log 23:267-270

Fullér R (2000) Introduction to neuro-fuzzy systems. Springer, Berlin

Goldberg H, Weaver G (1982) A strong completeness theorem for three-valued logic: part I. In: Leblanc H (ed) Existence, truth, and provability. State University of New York Press, Albany, pp 240-246

Gottwald S (1999) Many-valued logic and fuzzy set theory. In: Hohle U, Rodabaugh SE (eds) Mathematics of fuzzy sets. Logic, topology, and measure theory. Springer Science + Business Media, New York, pp 5-90

Gottwald S (2001) A treatise on many-valued logics. Research Studio Press, Taunton

Grandy R (2006) Many-valued, free, and intuitionistic logic. In: Jacquette D (ed) A companion to philosophical logic. Blackwell Publishing, Oxford, pp 531-544

Grigolia R (1997) Algebraic analysis of Łukasiewicz-Tarski’s $n$-valued logical systems. In: Wójcicki R, Malinowski G (eds) Selected papers on Łukasiewicz sentential calculi. Ossolineum, Wrocław, pp 81-92

Haack S (1996) Deviant logic, fuzzy Logic: beyond the formalism. The University of Chicago Press, Chicago

He H, He Z, Ma Y, Ai L (2007) Philosophical significance of universal logic—on second revolution of mathematical logic. In: Béziau J-Y, Costa-Leite A (eds) Perspectives on universal logic. Polimetrica International Scientific Publisher, Milano, pp 83-100

Humberstone L (2011) The connectives. The MIT Press, Cambridge

Hunter G (1971) Metalogic: an introduction to the metatheory of standard first order logic. University of California Press, Berkeley

Kabziński JK (1981) Many-valued logic. In: Marciszewski R (ed) Dictionary of logic as applied in the study of language. Springer, Dordrecht, pp 201-209

Karpenko AS (1989) Characterization of prime numbers in Łukasiewicz's logical matrix. Stud Logica 48:465-478

Łukasiewicz J (1967) Philosophical remarks on the many-valued systems of propositional logic. In: McCall S (ed) Polish logic 1920-1939. Clarendon Press, Oxford, pp 51-77

Malinowski G (2006) Many-valued logic. In: Jacquette D (ed) A companion to philosophical logic. Blackwell Publishing, Oxford, pp 545-561

Malinowski G (2007) Many-valued logic and its philosophy. In: Gabbay DM, Woods J (eds) Handbook of the history of logic, vol 8, the many valued and nonmonotonic turn in logic. North-Holland, Amsterdam, pp 13-94

Malinowski G (2009) A philosophy of many-valued logic. The third logical value and beyond. In: Lapointe $\mathrm{S}$ et al (eds) The golden age of Polish philosophy: logic, epistemology and the unity of science 16. Springer Science + Business Media, New York, pp 81-92

Mancosu P (2010) The adventure of reason: interplay between philosophy mathematics and mathematical logic 1900-1940. Oxford University Press, Oxford

Mancosu P, Zach R, Badesa C (2009) The development of mathematical logic from Russell to Tarski. In: Haaparanta L (ed) The development of modern logic. Oxford University Press, Oxford, pp 318-470

Mattila JK (2009) Many-valuation, modality, and fuzziness. In: Seising R (ed) Views on fuzzy sets and systems. Springer, Berlin, pp 271-300

Murawski R (2009) Philosophy of mathematics in the Lvov-Warsaw School. In: Lapointe S et al (eds) The golden age of Polish philosophy: logic, epistemology and the unity of science 16. Springer Science + Business Media, New York, pp 121-130

Negri S, von Plato J (2001) Structural proof theory. Cambridge University Press, Cambridge

Nguyen HT, Walker EA (2000) A first course in fuzzy logic. Chapman \& Hall/CRC, London

Priest G (2003) On alternative geometries, arithmetics, and logics: a tribute to Łukasiewicz. Stud Logica 74:441-468 
Prior AN (1953) Three-valued logic and future contingents. Philos Q 13:317-326

Rescher N (1968) Topics in philosophical logic. Synthese library 17. Springer, Dordrecht

Rescher N (1969) Many-valued logic. McGraw-Hill, New York

Rose A (1981) Many-valued logics. In: Agazzi E (ed) Modern logic—a survey. Springer, Dordrecht, pp 113-129

Rosser JB, Turquette AR (1952) Many-valued logics. North-Holland, Amsterdam

Schumann A, Smarandache F (2007) Neutrality and many-valued logics. American Research Press, Santa $\mathrm{Fe}$

Simons P (1989) Łukasiewicz, meinong and many-valued logic. In: Szaniawski K (ed) The Vienna circle and the Lvov-Warsaw School. Kluwer Academic Publishers, Dordrecht, pp 249-291

Skala HJ (1988) Essays on the history and development of many-valued logics and some related topics. In: Kacprzyk J, Fedrizzi M (eds) Combining fuzzy imprecision with probabilistic uncertainty in decision making. Springer, Berlin, pp 1-9

Słupecki J (1939) Proof of the axiomatizability of full many-valued systems of propositional calculus. Comptes rendus des séances de la Société des Sciences et des Lettres de Varsovie, Classe III $32: 110-128$

Słupecki J (1946) The complete three-valued propositional calculus. Annales Universitatis Mariae CurieSkłodowska 1:193-209

Słupecki J (1967) The full three-valued propositional calculus. In: McCall S (ed) Polish logic 1920-1939. Clarendon Press, Oxford, pp 335-337

Słupecki J, Bryll G, Prucnal T (1967) Some remarks on three-valued logic of Łukasiewicz. Stud Logica 21:45-66

Sudbery A (2016) The logic of the future in quantum theory. Synthese. doi:10.1007/s11229-016-1142-9

Tokarz M (1974) A method of axiomatization of Łukasiewicz logics. Bull Sect Log 3:21-24

Tomberlin JE (1971) The sea battle tomorrow and fatalism. Res 31:352-357

Tooley M (1997) Time, tense, and causation. Clarendon Press, Oxford

Tuziak R (1988) An axiomatization of the finite-valued Łukasiewicz calculus. Stud Logica 48:49-55

Urquhart A (2001) Basic many-valued logic. In: Gabbay DM, Guenthner F (eds) Handbook of philosophical logic, vol 2, 2nd edn. Kluwer Academic Publishers, Dordrecht, pp 249-295

Wajsberg M (1967) Axiomatization of the three-valued propositional calculus. In: McCall S (ed) Polish logic 1920-1939. Clarendon Press, Oxford, pp 264-284

Wan X-L, Chen M-Y (2014) The equivalent transformation between non-truth-function and truthfunction. In: Gou G, Liu Ch (eds) Scientific explanation and methodology of science. World Scientific Publishing, Singapore, pp 176-211

Wójcicki R (1973) Theory of logical calculi: basic theory of consequence operations. Synthese Library 199. Kluwer Academic Publishers, Dordrecht

Woleński J (1989) Logic and philosophy in the Lvov-Warsaw school. Synthese Library 198. Kluwer Academic Publishers, Dordrecht

Woleński J, Zygmunt J (1989) Jerzy Słupecki (1904-1987): life and work. Stud Logica 48:401-411

Zhang R, Phillis YA, Kouikoglou VS (2005) Fuzzy control of queuing systems. Springer, London 